\title{
Increased expression of Psoriasin is correlated with poor prognosis of bladder transitional cell carcinoma by promoting invasion and proliferation
}

\author{
JIA LIU ${ }^{1,2}$, ZEHANG ZHAO ${ }^{1}$, ZHIWEI SUN ${ }^{1,3}$, CHANG LIU $^{1}$, XIAOJING CHENG ${ }^{1,3}$, \\ FIONA RUGE ${ }^{1}$, YONG YANG ${ }^{2}$, WEN G. JIANG ${ }^{1}$ and LIN YE ${ }^{1}$ \\ ${ }^{1}$ Cardiff China Medical Research Collaborative, Division of Cancer and Genetics, Cardiff University School of Medicine, \\ Cardiff CF14 4XN, UK; ${ }^{2}$ Key Laboratory of Carcinogenesis and Translational Research, Department of \\ Urological Surgery, Peking University Cancer Hospital and Institute; ${ }^{3}$ Key Laboratory of Carcinogenesis and \\ Translational Research, Peking University Cancer Hospital and Institute, Beijing 100142, P.R. China
}

Received March 20, 2019; Accepted November 22, 2019

DOI: 10.3892/or.2019.7445

\begin{abstract}
Psoriasin, otherwise known as S100A7, is a member of the $\mathrm{S} 100$ protein family. With the key function of binding calcium, it is able to regulate a range of cellular functions. Altered Psoriasin expression is associated with poor clinical outcomes in several solid cancers. The present study aimed to examine the implication of Psoriasin in bladder cancer (BC). Expression of Psoriasin was examined in BC cell lines using PCR. Immunohistochemical (IHC) staining of Psoriasin was performed on a bladder disease spectrum tissue array. Plasmids were constructed to effectively knockdown and overexpress Psoriasin in BC cells and further utilized for in vitro BC cellular function assays. Association between Psoriasin expression and survival of patients with BC was evaluated using Kaplan-Meier survival analysis. Psoriasin was revealed to be expressed by both bladder epithelia and cancer cells as determined by IHC. Increased expression of Psoriasin was significantly correlated with a poor overall BC patient survival. Overexpression of Psoriasin in the EJ138 cell line increased cellular proliferation, adhesion and invasion, whereas knockdown exhibited the opposite effect on cellular functions in RT112 cells. Matrix metalloprotease (MMP)9 appeared to be the most affected of the three MMPs examined in these two BC cell lines. The analysis revealed a positive correlation in $\mathrm{BC}$ tumours between Psoriasin and MMP9. Overall, high Psoriasin expression was correlated with poor overall survival in BC patients and promoted invasiveness of BC cells via upregulation of MMPs. Psoriasin possesses certain prognostic and therapeutic potential in $\mathrm{BC}$ which requires further exploration.
\end{abstract}

Correspondence to: Dr Lin Ye, Cardiff China Medical Research Collaborative, Division of Cancer and Genetics, Cardiff University School of Medicine, Academic Avenue, Heath Park, Cardiff CF14 4XN, UK

E-mail: yel@cf.ac.uk

Key words: Psoriasin, BC, invasion, matrix metalloproteinase, survival

\section{Introduction}

Worldwide, bladder cancer (BC) is the seventh commonest malignant tumour in men and the eleventh most common tumour for both sexes. The age-standardised incidence rate (per 100,000 person/years) is 9.0 for men and 2.2 for women worldwide, and 19.1 for men and 4.0 for women in Europe specifically (1). The majority of bladder tumours are transitional cell carcinomas (TCCs), with approximately $80 \%$ being noninvasive papillary transitional-cell carcinomas that are frequently amenable to surgical resection. Unfortunately, 50-70\% of patients develop tumour recurrence and of those that do, $15 \%$ have more advanced disease. These patients with advanced disease invading the muscle of the bladder, have a significantly reduced 5-year survival rate, due to the increased incidence of metastases and failure of available treatments $(2,3)$. Of those patients that present at diagnosis with locally advanced, bladder muscle invasive TCC, 50\% relapse with metastatic diseases (4). These poor outcomes, particularly in those with metastatic BC, require a better understanding of $\mathrm{BC}$ disease progression, such that improvements can be made for $\mathrm{BC}$ patients.

Psoriasin (otherwise known as S100A7) is an 11.4-kDa secreted protein located on chromosome 1q21 and belongs to the S100 protein family (5). In normal human tissues, expression of Psoriasin is commonly confined to the epithelia, having been initially identified as highly expressed in the epidermis of psoriatic skin (6). In terms of cellular functions it is known to influence calcium binding and signalling, thus affecting cellular proliferation, differentiation, migration and apoptosis (7).

It is of no surprise therefore that aberrant Psoriasin is associated to numerous human diseases including cancer. Psoriasin overexpression is observed in breast (8), skin (9), head and neck (10), prostate (11) and lung cancers (12). In breast cancer, upregulated Psoriasin expression is observed particularly in ductal carcinoma in situ and invasive tumours that are oestrogen and progesterone receptor negative (13). Higher Psoriasin expression was associated with poor prognosis and survival. In addition to the apparent effect on the proliferation, adhesion and invasion of cancer cells, Psoriasin 
can also actively engage in tumour microenvironment and signal transduction. For example, Psoriasin is able to promote neoangiogenesis by interacting with the receptor for advanced glycation end products (RAGE), which results in vascular endothelial growth factor (VEGF) upregulation (14). Psoriasin can also promote EGF-induced activation of EGFR with a consequent impact on migration and invasion of a ER-negative breast cancer cell line, i.e. MDA-MB-231 (15). Psoriasin was revealed to be highly expressed and secreted by bladder squamous cancer cells $(16,17)$. Determining the protein level of Psoriasin in urine has been proposed for early detection and monitoring the disease progression $(18,19)$.

To date, the expression of Psoriasin in bladder transitional cell carcinoma and its influence on BC cellular function remain unknown. The present study aimed to investigate the role played by Psoriasin in $\mathrm{BC}$, particularly the most common type of $\mathrm{BC}$, i.e. transitional cell carcinoma.

\section{Materials and methods}

Materials and cell lines. The human BC cell lines EJ138 (ECACC 85061108) and RT112 (ECACC cat. no. 85061106; European Collection of Animal Cell Culture) were routinely cultured in DMEM-F12 medium, with 10\% fetal bovine serum supplementation and antibiotics. The EJ138 cell line (ECACC 85061108) is the same cell line as T24 shown by both isoenzyme analysis and human leukocyte antigen (HLA) profiles. Monoclonal mouse anti-Psoriasin and monoclonal mouse anti-glyceraldehyde-3-phosphate dehydrogenase (GAPDH) antibodies were obtained from Novus Biologicals (Novus Biologicals LLC) and Santa Cruz Biotechnology, Inc., respectively. All other reagents were obtained from Sigma-Aldrich; Merk KGaA. A bladder disease spectrum (urocystic cancer progression) tissue array (BL804) was purchased from US Biomax, Inc.

Online data for gene expression profile in $B C$. Three different online datasets were included in the present study. GSE3167 includes normal urothelium $(n=9)$, superficial transitional cell carcinoma (STCC) without carcinoma in situ (CIS) $(n=15)$, STCC with CIS $(n=13)$, invasive carcinoma $(n=13)$, CIS $(n=5)$ and normal mucosa $(n=5)(20)$. Another cohort of BC was GSE32549 which is comprised of BCs of different T stages: Ta T1 and T2 (21). A BC cohort from The Cancer Genome Atlas (TCGA) was included for a survival analysis using an online tool (http://ualcan.path.uab.edu) (22).

Vector construction for Psoriasin overexpression and knockdown. Anti-human Psoriasin hammerhead ribozymes and Psoriasin overexpression plasmid vectors were developed and used in our previous study (11). The Psoriasin overexpression and control plasmids were transfected into EJ138 cells, while ribozyme transgene Psoriasin knockdown and control were employed in the RT112 cell line. Stable transfectants were obtained and verified after 3 weeks of selection using blasticidin $(5 \mu \mathrm{g} / \mathrm{ml})$. The selected cells were subsequently maintained in the medium containing $0.5 \mu \mathrm{g} / \mathrm{ml}$ blasticidin and used for the following experiments.

RNA isolation, reverse transcription-PCR (RT-PCR) and quantitative PCR (qPCR). TRIzol Reagent (Sigma-Aldrich;
Merck $\mathrm{KGaA}$ ) was used for total RNA extraction and cDNA was synthesised using iScript cDNA Synthesis kit (Bio-Rad Laboratories, Inc.). REDTaq ReadyMix PCR reaction mix (primer sequences presented in Table I) was utilised for PCR under the following cycling conditions: $95^{\circ} \mathrm{C}$ for $5 \mathrm{~min}$, followed by 36 cycles at $95^{\circ} \mathrm{C}$ for $30 \mathrm{sec}, 55^{\circ} \mathrm{C}$ for $30 \mathrm{sec}, 72^{\circ} \mathrm{C}$ for $40 \mathrm{sec}$ and a final extension at $72^{\circ} \mathrm{C}$ for $10 \mathrm{~min}$.

qPCR of BC cell cDNA samples was performed using the Icycler IQ5 system (Bio-Rad Laboratories, Inc.), the Amplifluor system (Intergen, Inc.) and qPCR Mastermix (Bio-Rad Laboratories, Inc.) to identify Psoriasin transcript expression, along with standards and negative controls. Psoriasin primers were designed using Beacon design software (Premier Biosoft International), with additional $\mathrm{Z}$ sequence (5'-ACTGAACCT GACCGTACA) on the reverse primer complementary to the universal $\mathrm{Z}$ probe (Intergen, Inc.). Reaction conditions were as follows: $95^{\circ} \mathrm{C}$ for $12 \mathrm{~min}$, followed by 90 cycles at $95^{\circ} \mathrm{C}$ for $15 \mathrm{sec}, 55^{\circ} \mathrm{C}$ for $40 \mathrm{sec}$ and $72^{\circ} \mathrm{C}$ for $20 \mathrm{sec}$.

Immunohistochemical (IHC) staining for Psoriasin. A bladder disease spectrum tissue array (TMA) (BL804) was purchased from US Biomax, Inc. The TMA was de-paraffinised followed by a 20-min incubation with TBS for rehydration. A further 20-min incubation in $0.6 \%$ BSA blocking solution was followed by the primary antibody (anti-Psoriasin; dilution 1:100; cat. no. 47C1068; Novus Biologicals, Ltd.) for $1 \mathrm{~h}$ at room temperature. After washing, the sections were incubated in the secondary biotinylated antibody (dilution 1:25; biotinylated universal pan-specific antibody, horse anti-mouse/rabbit/goat IgG, cat. no. BA-1300; Vector Laboratories, Inc.) at room temperature for $30 \mathrm{~min}$. An avidin-biotin complex (Vector Laboratories, Inc.) was applied to the TMA and diaminobenzidine chromogen (Vector laboratories, Inc.) was added in the dark for 5 min. Counterstaining of the nuclei was performed using Gill's hematoxylin (H-3401; Vector Laboratories, Inc.). The TMA was dehydrated with increasing grades of methanol, then cleared in xylene and mounted.

Cell proliferation assay. Cells were plated into a 96-well plate (2,000 cells/well for EJ138 and 4,000 cells/well for RT112) and proliferation was determined over a period of up to 5 days. Cells were stained with $0.5 \%$ crystal violet at room temperature for $10 \mathrm{~min}$ and the absorbance was read at a wavelength of $540 \mathrm{~nm}$ using a spectrophotometer (Elx800; Bio-Tek Instruments, Inc.).

In vitro invasion assay. Matrigel (50 $\mu \mathrm{g})$ (BD Matrigel Basement Membrane Matrix, cat. no. 354234; BD BioSciences) was used to coat Transwell inserts and air-dried. The coating layer was rehydrated before use. Cells $(20,000)$ were added to each insert and after $48 \mathrm{~h}$ of incubation at $37^{\circ} \mathrm{C}$, any cells remaining in the insert were removed with a cotton tip swab and the cells that had invaded through the Matrigel were fixed in $4 \%$ formalin at room temperature for $30 \mathrm{~min}$, stained with $0.5 \%$ crystal violet for $10 \mathrm{~min}$ at room temperature, and counted under microscope with a magnification of $\mathrm{x} 200$.

Cell-matrix adhesion assay. Cells (40,000) were placed in each well of previously prepared 96-well plates coated 
Table I. Primer sequences for PCR and qPCR.

\begin{tabular}{lll}
\hline Primer & \multicolumn{1}{c}{ Forward } & \multicolumn{1}{c}{ Reverse } \\
\hline Psoriasin & 5'-GAGGTCCATAATAGGCATGA-3' & 5'-AGCAAGGACAGAAACTCAGA-3' \\
Psoriasin (qPCR) & 5'-TGTGACAAAAAGGGCACAAA-3' & 5'-ACTGAACCTGACCGTACACCCA \\
& & GCAAGGACAGAAACTC-3' \\
GAPDH & 5'-GGCTGCTTTTAACTCTGGTA-3' & 5'-GACTGTGGTCATGAGTCCTT-3' \\
GAPDH (qPCR) & 5'-CTGAGTACGTCGTGGAGTC-3' & 5'-ACTGAACCTGACCGTACAGAGA \\
& & TGATGACCCTTTTG-3' \\
Psoriasin ribozyme & 5'-CTGCAGTCACAGGCACTAAGGAAG & 5'-ACTAGTGGCTGGTGTTTGACATT \\
& TTGGGCTGATGAGTCCGTGAGGA-3' & TCGTCCTCACGGACT-3' \\
\hline
\end{tabular}

with Matrigel (5 $\mu \mathrm{g} /$ well). Plates were incubated at $37^{\circ} \mathrm{C}$ for $45 \mathrm{~min}$. Media was then discarded and nonadherent cells were removed by BSS buffer wash. The remaining adherent cells were fixed for $10 \mathrm{~min}$ in $4 \%$ formaldehyde, followed by a BSS wash and $0.5 \%$ crystal violet staining at room temperature for $10 \mathrm{~min}$. The number of adherent cells was then counted under a microscope with a magnification of $\mathrm{x} 200$.

Wound/scratch assay. Cells were seeded at a density of 20,000 cells/well for EJ138 and 40,000 cells/well for RT112 into a 24-well plate and cultured until confluency. After creation of a scratch/wound, the movement of cells to close the wound was recorded using an inverted microscope equipped with an incubation chamber with a magnification of x100 (EVOS FL Auto2; Life Technologies; Thermo Fisher Scientific, Inc.). The movement of the cells was quantified using ImageJ (Version 1.48; https://imagej.nih.gov/ij/).

Western blotting. Cells were lysed using a buffer comprising $150 \mathrm{mM} \mathrm{NaCl}, 50 \mathrm{mM}$ Tris, $0.02 \%$ sodium azide, $0.5 \%$ sodium deoxycholate, $1.5 \%$ Triton $\mathrm{X}-100(\mathrm{v} / \mathrm{v}), 1 \mu \mathrm{g} / \mathrm{ml}$ aprotinin, $5 \mathrm{mM}$ Na3VO4, $1 \mu \mathrm{g} / \mathrm{ml}$ leupeptin, $100 \mu \mathrm{g} / \mathrm{ml}$ phenylmethylsulphonylfluoride, $0.1 \%$ sodium dodecyl sulfate and $100 \mu \mathrm{M}$ dithiothreitol. Protein concentration was determined using the Bio-Rad DC Protein Assay (500-0116; Bio-Rad Laboratories, Ltd). Protein (20 $\mu \mathrm{g}$ per lane) was loaded and separated in $12 \%$ sodium dodecyl sulfate-polyacrylamide gel (SDS-PAGE) followed by tra-nsfer on to polyvinylidene difluoride membranes. Initial 1-h membrane blocking used 5\% fat-free milk in tris (hydroxymethyl) aminomethane-buffered saline (TBS) ( $\mathrm{pH} 7.5)$ at room temperature, followed by incubation with mouse anti-Psoriasin (1:1,000; cat. no. 47C1068; Novus Biologicals, Ltd.), mouse anti-MMP2 (1:1,000; cat. no. sc-13595), mouse anti-MMP7 (1:1,000; cat. no. sc-58388), rabbit anti-MMP9 $(1: 1,000$; cat. no. sc-10737) or mouse anti-GAPDH (1:1,000; cat. no. sc-47724; all from Santa Cruz Biotechnology, Inc.) antibodies overnight at $4^{\circ} \mathrm{C}$. The appropriate horseradish peroxidase-conjugated secondary antibodies (A5278 anti-mouse IgG, A6154 anti-rabbit IgG; Sigma-Aldrich; Merck KGaA) were applied at room temperature for $1 \mathrm{~h}$. Visualisation of the membranes after incubation with a chemiluminescence reagent used the Syngene gel documentation system (G:BOX Chemi XRQ; GeneSys version 1.5.6.0; Syngene UK).
Statistical analysis. Analysis was performed using SPSS 17.0 software (SPSS Inc.). The Mann-Whitney U test was employed to analyse non-normally distributed data, while the two-sample t-test was utilised for normally distributed data. Pearson correlation test was used for the correlation analysis. A P-value at $<0.05$ was considered to indicate a statistically significant difference.

\section{Results}

Expression of Psoriasin in BC tissues, and correlation with clinicopathological features of $B C$. The expression of Psoriasin in $\mathrm{BC}$ was first evaluated using two gene array datasets. In the cohort (GSE3167) comprised of normal urothelium, superficial transitional cell carcinoma (STCC) without/with carcinoma in situ (CIS), invasive carcinoma, CIS and normal mucosa, the expression of Psoriasin was increased in the invasive carcinomas (Fig. 1A). This was further supported by analyses of Psoriasin in the other cohort of BC (GSE32549), which revealed an increased expression of Psoriasin in invasive BCs including both T1 and T2 tumours compared with Ta tumours which were confined within the innermost layer of the bladder lining (Fig. 1B). To investigate how Psoriasin expression may relate to clinical prognosis, Kaplan-Meier survival analysis was performed for Psoriasin expression in the TGGA BC cohort using an online tool (http://ualcan.path.uab.edu/cgi-bin/). It was revealed that a high level of Psoriasin expression was significantly correlated with poor overall survival in $\mathrm{BC}$ patients $(\mathrm{P}=0.015$, Fig. $1 \mathrm{C})$. With regard to Psoriasin protein expression levels, IHC analysis of Psoriasin in a human bladder disease spectrum tissue array demonstrated weak to moderate staining in normal urocystic tissues, hyperplasia and chronic inflammation of mucosa (Fig. 1D and Table II). Psoriasin was weakly expressed or absent from T1 TCC tumours. Strong staining was observed in 2 of the 19 T2 TCC tumours. Strong and extensive staining was observed in 3 out of 5 squamous cell carcinomas.

Knockdown and overexpression of Psoriasin in BC cell lines. Two BC cell lines were examined for mRNA expression of Psoriasin using RT-PCR (Fig. 2A). The expression of Psoriasin was relatively higher in RT112 cells in comparison with EJ138 cells. This allowed us to examine the function of Psoriasin in $\mathrm{BC}$ cells using these two cell lines to create a pair of opposite models, i.e. knockdown of Psoriasin in the RT112 cell line and overexpression of Psoriasin in the EJ138 cell line. Psoriasin 
Table II. IHC staining of Psoriasin in bladder tissues.

\begin{tabular}{|c|c|c|c|c|c|}
\hline & $\mathrm{N}$ & Negative & Weak & Moderate & Strong \\
\hline \multicolumn{6}{|l|}{ Transitional cell carcinoma } \\
\hline $\mathrm{T} 1$ & 10 & 5 & 4 & 1 & 0 \\
\hline $\mathrm{T} 2$ & 19 & 8 & 7 & 2 & 2 \\
\hline $\mathrm{T} 3$ & 1 & 0 & 1 & 0 & 0 \\
\hline Tx & 1 & 0 & 0 & 1 & 0 \\
\hline Transitional cell carcinoma & 30 & 13 & 12 & 3 & 2 \\
\hline Squamous cell carcinoma & 5 & 0 & 1 & 1 & 3 \\
\hline Adenocarcinoma & 2 & 2 & 0 & 0 & 0 \\
\hline Undifferentiated carcinoma & 1 & 1 & 0 & 0 & 0 \\
\hline Sarcomatoid carcinoma & 3 & 2 & 1 & 0 & 0 \\
\hline Metastasis & 3 & 0 & 2 & 0 & 1 \\
\hline Normal & 6 & 0 & 6 & 0 & 0 \\
\hline Adjacent normal & 5 & 1 & 4 & 0 & 0 \\
\hline Inflammation & 8 & 1 & 3 & 3 & 1 \\
\hline Hyperplasia & 12 & 0 & 6 & 5 & 1 \\
\hline Benign & 5 & 2 & 2 & 1 & 0 \\
\hline
\end{tabular}
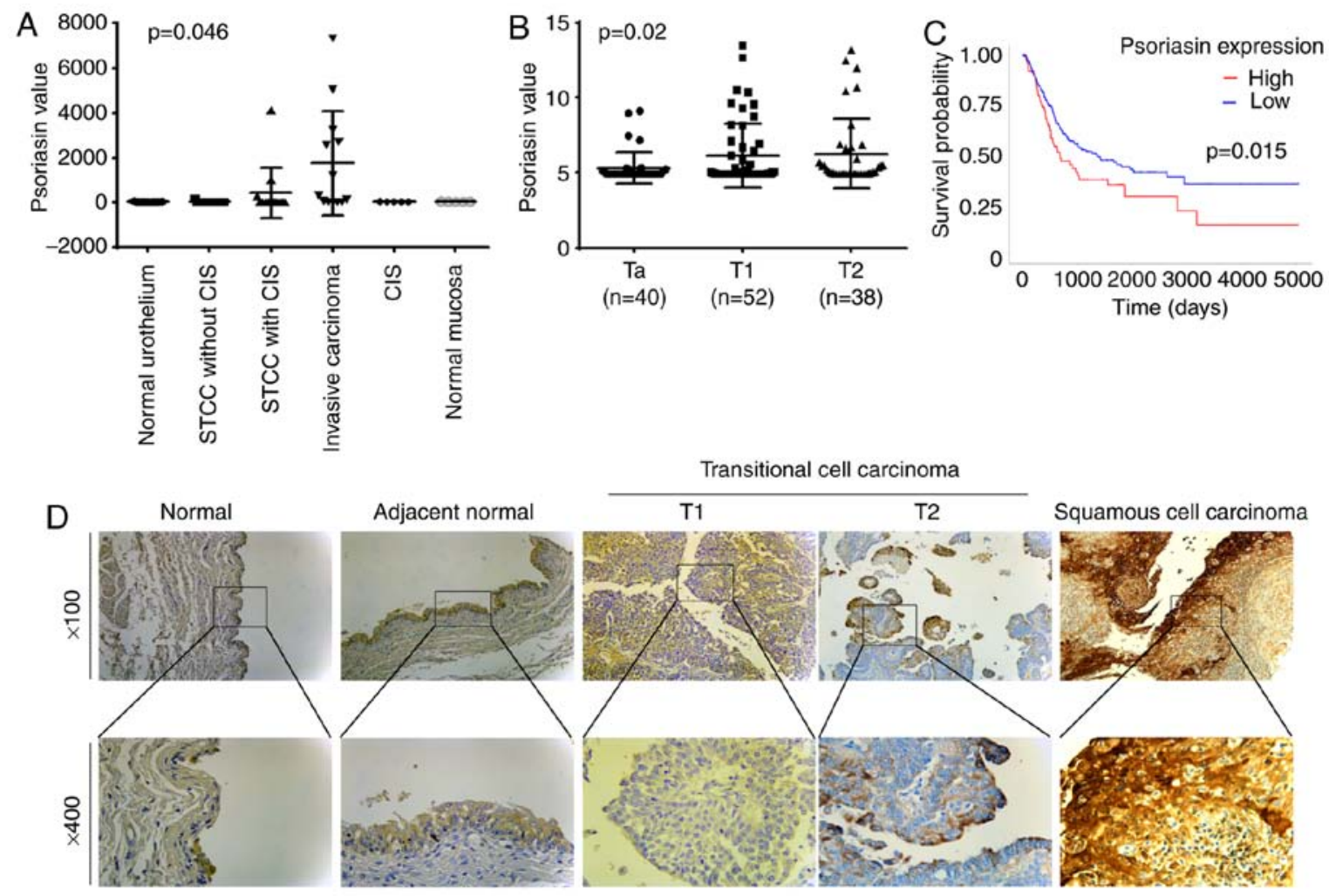

Figure 1. Expression of Psoriasin in BC. (A) Psoriasin expression in a cohort of BC (GSE3167) comprised of normal urothelium ( $\mathrm{n}=9$ ), STCC without CIS $(n=15)$, STCC with CIS ( $n=13)$, invasive carcinoma ( $n=13)$, CIS $(n=5)$ and normal mucosa $(n=5)(20)$. (B) Psoriasin expression was also analysed in another gene expression array dataset (GSE32549) which was comprised of non-invasive papillary carcinoma (Ta, n=40), T1 ( $\mathrm{n}=52)$ and T2 (n=38) (21). (C) Kaplan-Meier survival analysis indicated the expression of Psoriasin was associated with a poor overall survival (TCGA BC). The cutoff value is the 25 th percentile. (D) Differential expression of Psoriasin was detected in normal urocystic tissues, adjacent normal urocystic tissue, transitional cell carcinomas and squamous cell carcinoma (BL804, US Biomax) using IHC. BC, bladder cancer; STCC, superficial transitional cell carcinoma; CIS, carcinoma in situ; TCGA, The Cancer Genome Atlas; IHC, immunohistochemical.

knockdown in RT112 and overexpression in EJ138 cell lines was achieved using anti-Psoriasin ribozyme and Psoriasin expressing plasmid vectors, respectively. Psoriasin expression was confirmed in the transfected cells using RT-PCR (Fig. 2A) and qPCR (Fig. 2B). Overexpression of Psoriasin was established in EJ138 (EJ138 ${ }^{\text {PsoExp }}$ ) compared with EJ138 plasmid 
A

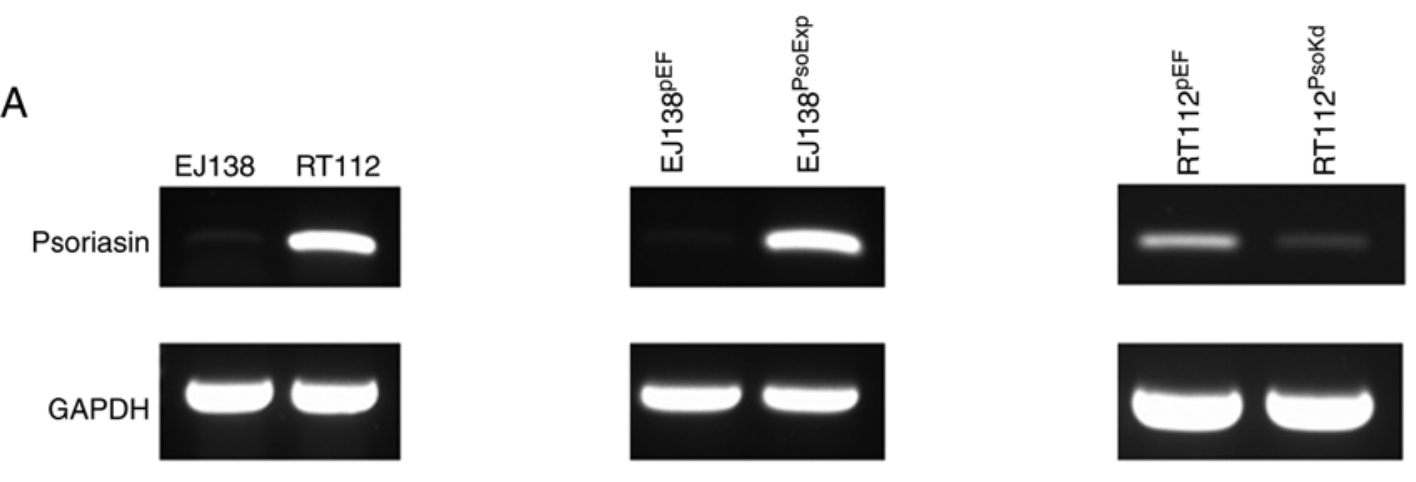

B

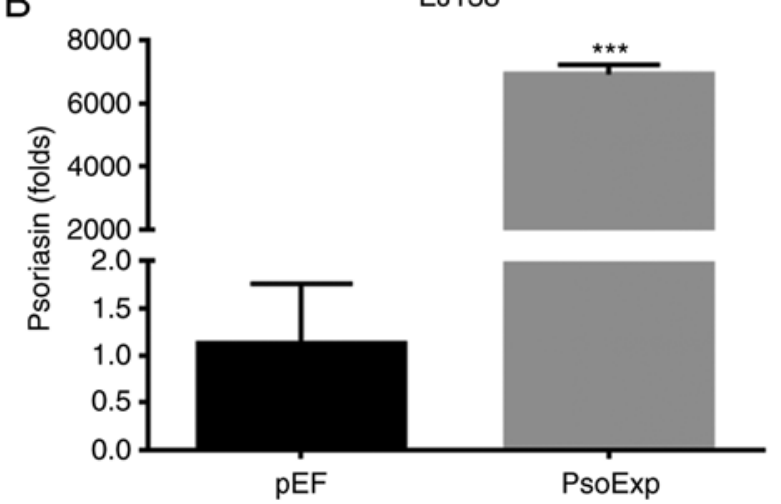

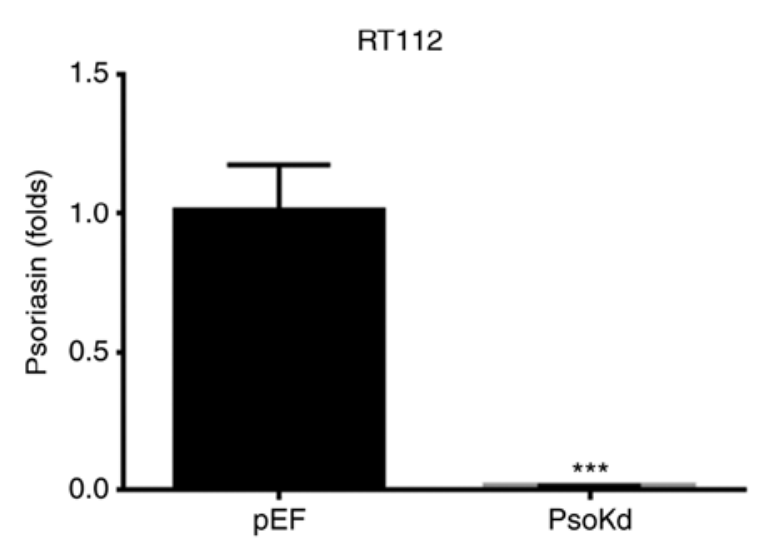

Figure 2. Expression of Psoriasin in BC cell lines. (A) Expression of Psoriasin in EJ138 and RT112 cell lines (left panel) was examined using PCR. EJ138 (middle panel) and RT112 (right panel) were transfected with Psoriasin overexpression vectors (EJ138 ${ }^{\text {PsoExp }}$ ) and Psoriasin ribozyme vectors (RT112 ${ }^{\text {PsoKd }}$, respectively. The empty plasmid vector (pEF) was used as control for the transfection and selection. (B) Psoriasin expression was further verified using real time PCR. ${ }^{* * *} \mathrm{P}<0.001$. BC, bladder cancer.

vector control (EJ138 $8^{\mathrm{pEF}}$ ), while decreased expression of Psoriasin was revealed in the RT112 Psoriasin knockdown cells (RT112 ${ }^{\text {PsoKd }}$ ) in comparison with and RT112 plasmid vector control (RT112 $\left.{ }^{\mathrm{pEF}}\right)$.

Influence of Psoriasin overexpression and knockdown on BC cellular proliferation in vitro. Increased proliferation was observed in EJ138 cells which had Psoriasin overexpressed. EJ138 ${ }^{\text {PsoExp }}$ cells had a significantly increased proliferation rate, compared to the control $(\mathrm{P}<0.001$; Fig. 3A). Conversely in RT112 cells in which Psoriasin had been knocked down (RT112 $\left.{ }^{\text {PsoKd }}\right)$ there was decreased proliferation, compared to the control $(\mathrm{P}<0.001$; Fig. $3 \mathrm{~B})$.

Influence of Psoriasin overexpression and knockdown on BC cellular adhesion in vitro. The influence of Psoriasin on the adhesive nature of $\mathrm{BC}$ cells was examined, with EJ138 ${ }^{\text {PsoExp }}$ cells significantly increased in their adhesive capacity compared to the EJ138 ${ }^{\mathrm{pEF}}$ control cells, $(\mathrm{P}<0.001$; Fig. $3 \mathrm{C})$. Whereas knockdown of Psoriasin resulted in a significant decrease in adhesiveness of RT112 ${ }^{\text {PsoKd }}$ cells, compared with the corresponding control ( $\mathrm{P}<0.001$; Fig. 3D).

Effects of Psoriasin on in vitro migration of BC cells. A wound, or scratch assay was utilised to determine the migratory capacity of BC cells with either Psoriasin overexpression or knockdown. Notably, the EJ138 ${ }^{\text {PsoExp }}$ Psoriasin overexpressing cells did not exhibit any significant alteration in migration compared to the control (Fig. 4A). A similar result was also observed in RT112 $2^{\text {Psokd }}$ cells, in which the motility was similar to that of the RT112 ${ }^{\mathrm{pEF}}$ cells (Fig. 4B).

Effects of Psoriasin on invasion of BC cells. The EJ138 ${ }^{\text {PsoExp }}$ Psoriasin over-expressing cells demonstrated a significant increase of invasion, compared to the control $(\mathrm{P}<0.001$; Fig. 5A). Conversely, this was also confirmed with RT112 $2^{\text {Psokd }}$ Psoriasin-knockdown cells that appeared to be significantly less invasive compared with the RT112 ${ }^{\mathrm{pEF}}$ cells (Fig. 5B).

Psoriasin regulates the function of BC cells via MMPs. In our previous study of Psoriasin in prostate cancer, MMPs were revealed to be involved in Psoriasin-promoted invasiveness of prostate cancer cells (11). Therefore, the MMP protein present in EJ138 and RT112 cells was analysed. Increased expression of MMP9 was observed in EJ138 ${ }^{\text {PsoExp }}$ cells, and reduced expression of MMP9 was present in RT112 ${ }^{\text {Psokd }}$ cells. There was no evident alterations observed in the expression of MMP2 and MMP7 (Fig. 6A). To further investigate the relationship between MMP9 and Psoriasin, TCGA online data was used again (http://www.linkedomics.org/admin.php) and a positive correlation between the mRNA expression of Psoriasin and MMP9 was revealed ( $\mathrm{P}<0.05$; Fig. 6B).

\section{Discussion}

TCC has a five-year survival rate of $>95 \%$ for patients with small single foci, well-differentiated papillary tumours compared to near $0 \%$ survival in those patients with locally 


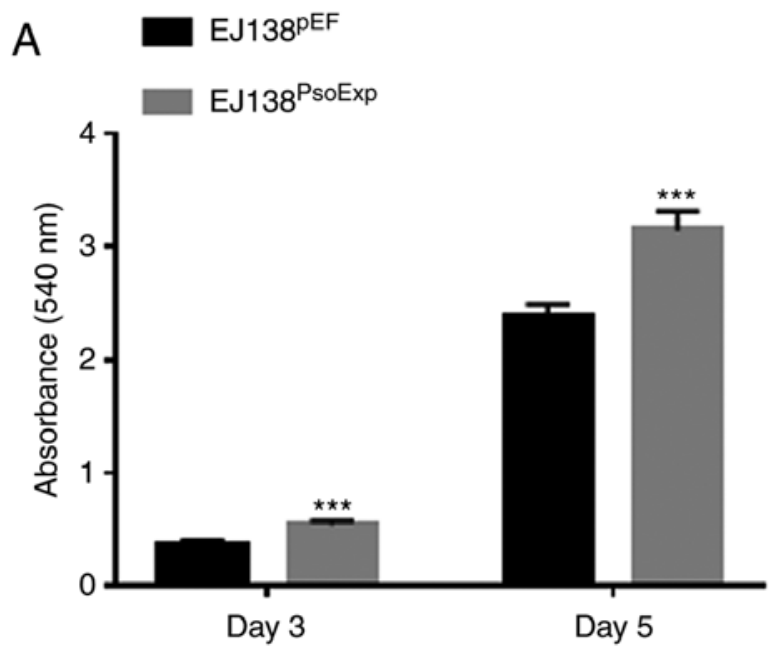

C EJ138
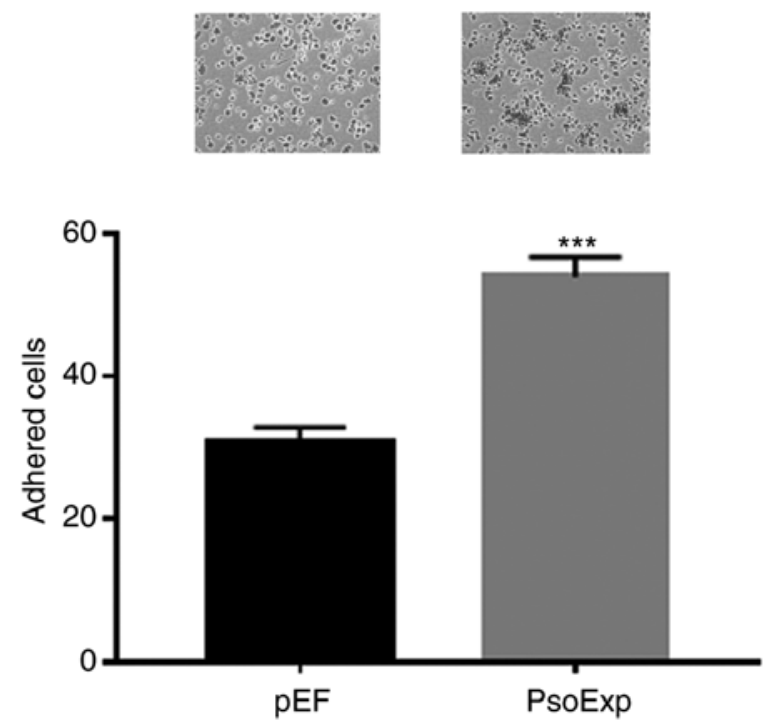

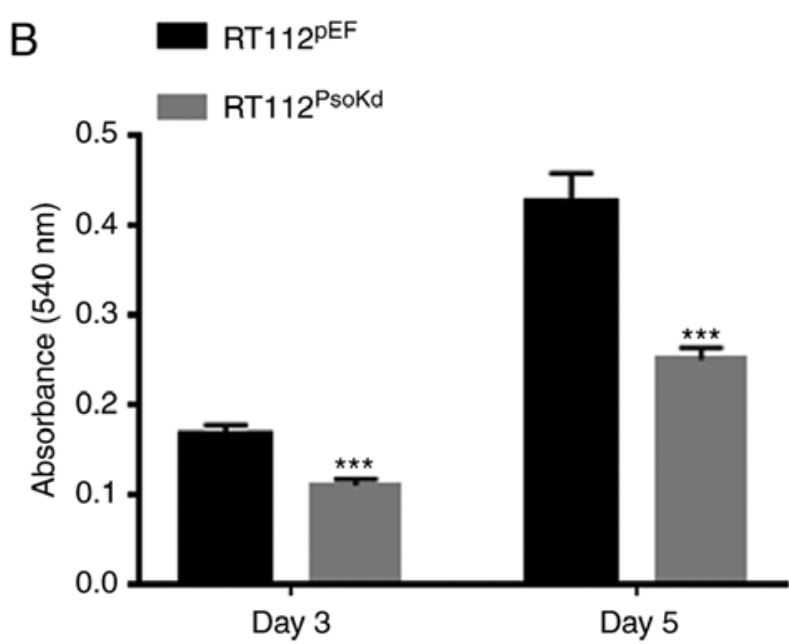

D

RT112
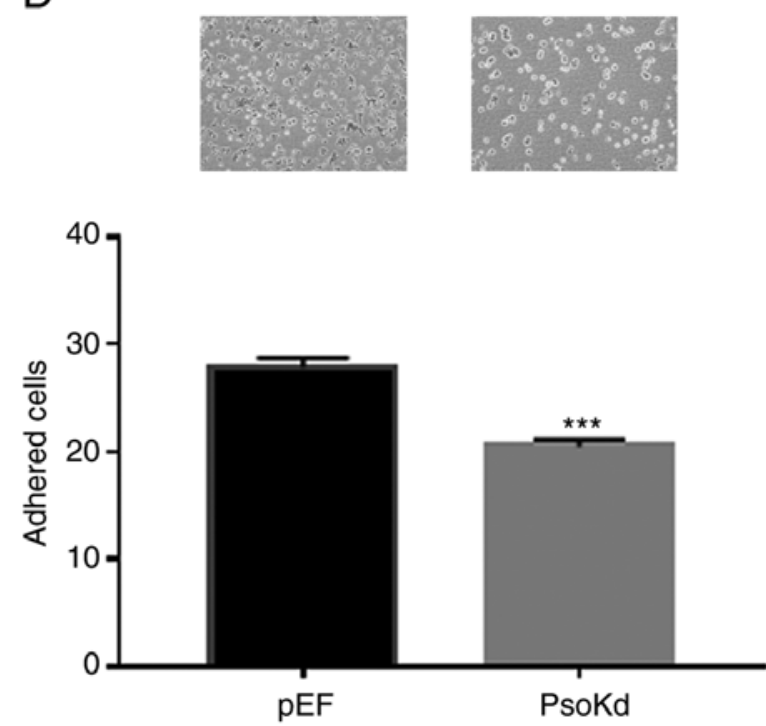

Figure 3. Influence of Psoriasin on in vitro growth and adhesion of BC cells. (A) Growth of EJ138 $8^{\mathrm{Ps} \text { Exp }}$ cells was examined in comparison with EJ138 $8^{\mathrm{pEF}}$ control

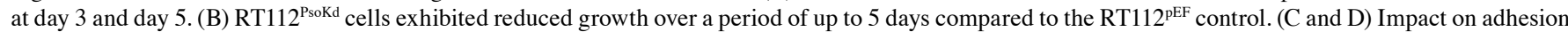
to Matrigel was determined in (C) EJ138 and (D) RT112 cells. Three independent experiments were performed. ${ }^{* * *} \mathrm{P}<0.001$. BC, bladder cancer.

advanced disease and gross nodal metastases (23). Despite efforts towards early detection and treatment, there is still a significant clinical impact on patients with invasive $\mathrm{BC}$, including the morbidity of disease recurrence and progression, to the mortality inevitably associated with metastases.

Psoriasin was first discovered as being highly expressed in the overproliferative epidermis of psoriatic skin lesions (24). Subsequent studies of Psoriasin have implied a role in promoting tumour progression, particularly in breast cancer and pancreatic cancer, where tumours with high Psoriasin expression had greater metastasis and poor prognosis $(8,25)$. Increased Psoriasin protein has also been detected in the sera of patients with squamous cell carcinomas of the lung (26). In the present study, Psoriasin expression was examined in a human bladder disease spectrum tissue array. Psoriasin was weakly expressed or absent from the normal bladder tissues, while increased expression was observed in invasive $\mathrm{BCs}$ and squamous cell BCs. Highly expressed Psoriasin evident in the squamous cell BCs was in line with our previous observation of Psoriasin in lung cancers (12) and also findings in bladder squamous cell carcinomas (17). The present analyses also revealed that Psoriasin expression was upregulated in invasive BCs. These results indicated that Psoriasin plays an important role during the progression of BC, particularly with local invasion. Kaplan-Meier survival analysis revealed that the elevated expression levels of Psoriasin were associated with the overall survival of patients with BC.

The present study demonstrated that in vitro, overexpression of Psoriasin resulted in an increase of proliferation, invasion and motility of BC cells. Conversely Psoriasin knockdown exhibited the opposite impact on these cellular functions. The regulatory role of Psoriasin on the cellular functions in BC cells is in keeping with findings from studies of Psoriasin in other malignancies $(11,25,27)$. It suggests that Psoriasin plays a positive role during the invasive growth/expansion of BC. 

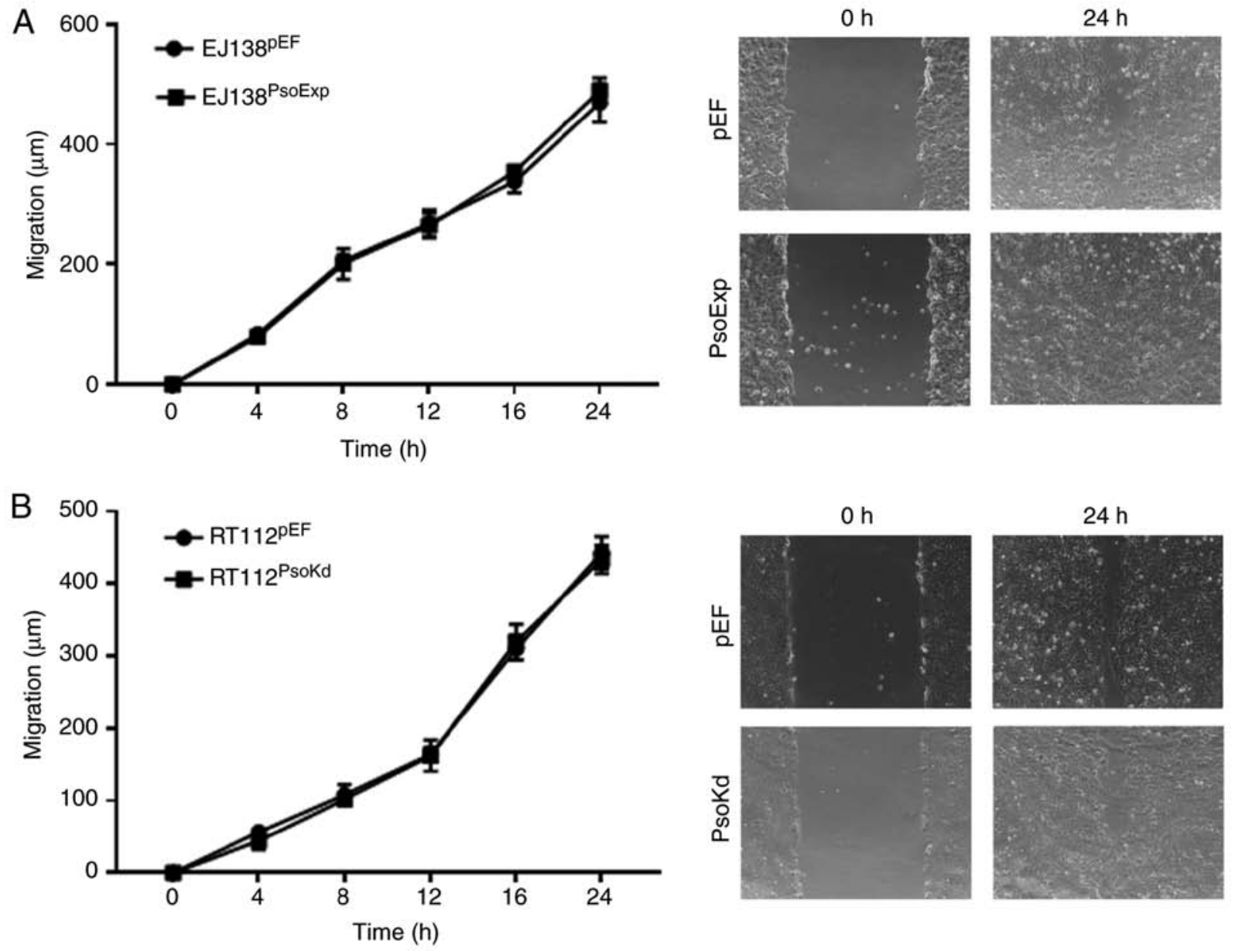

Figure 4. Effect of altered Psoriasin expression on the migration of BC cells. Migration of (A) EJ138 $8^{\text {PsoExp }}$ cells and (B) RT112 ${ }^{\text {PsoKd }}$ cells was determined using a wound healing assay in comparison with the corresponding controls. BC, bladder cancer.

A
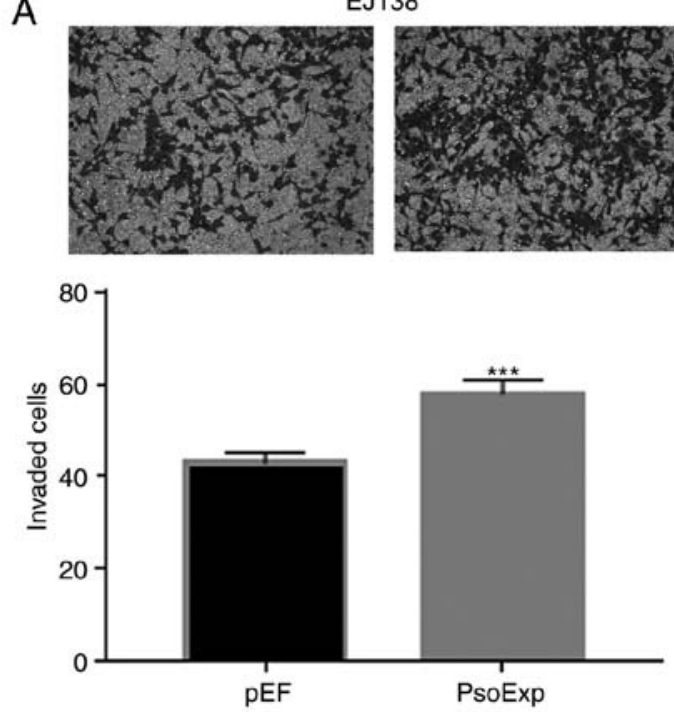

B

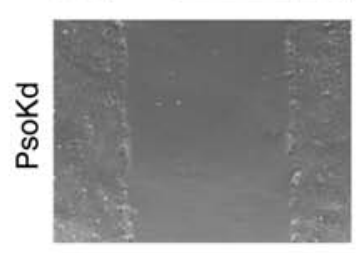

B

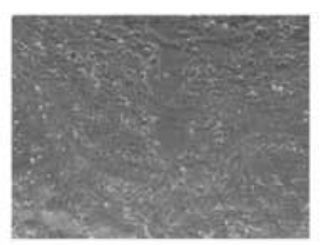

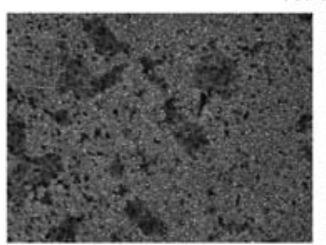
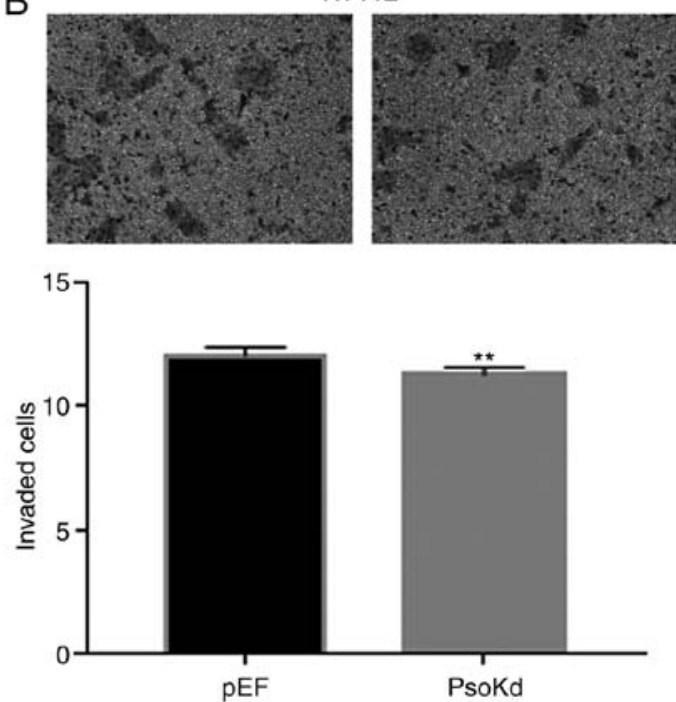

Figure 5. Psoriasin overexpression and knockdown alters the invasiveness of BC cells. Transwell invasion assay was employed to determine the influence of Psoriasin overexpression and knockdown on the invasion of (A) EJ138 and (B) RT112 cell lines, respectively. Three independent experiments were carried out. ${ }^{* *} \mathrm{P}<0.01$ and ${ }^{* * *} \mathrm{P}<0.001 . \mathrm{BC}$, bladder cancer.

In contrast to the inverse correlation between Psoriasin expression and adhesion observed in previous studies of other cancers $(11,12,25)$, Psoriasin overexpression in EJ138 cells enhanced their adhesion while an opposite effect on adhesion was evident in the RT112 Psoriasin-knockdown cells. This phenomenon is consistent with some observations in clinical 


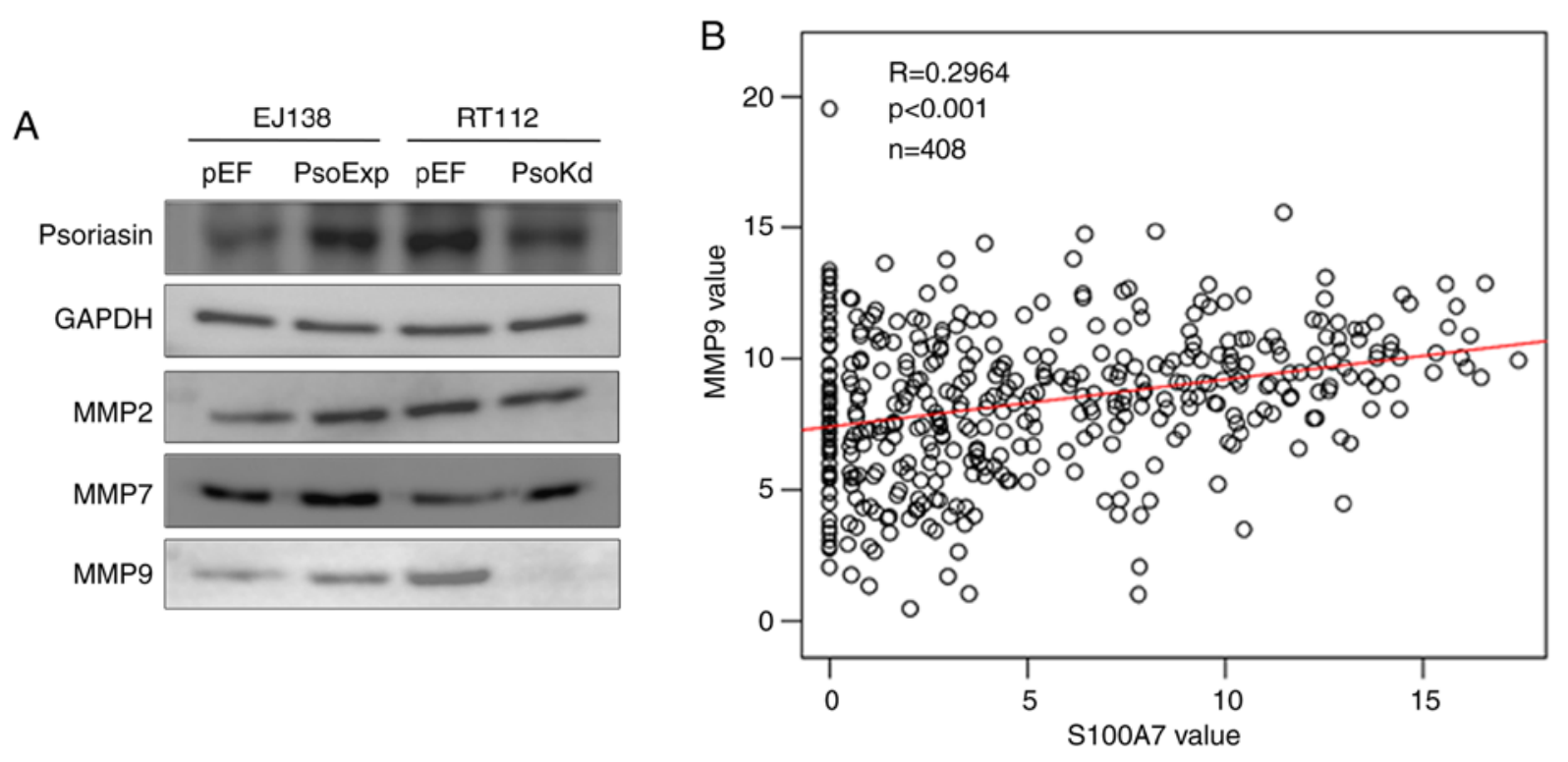

Figure 6. MMP9 is involved in the Psoriasin-regulated invasiveness of BC cells. (A) MMP2, MMP7 and MMP9 were determined in both EJ138 ${ }^{\text {PsoExp }}$ and RT112 ${ }^{\text {PsoKd }}$ cells compared with their respective controls using western blot analysis. (B) Correlation between Psoriasin and MMP9 in TCGA cohort of BC was analysed using Pearson correlation test. BC, bladder cancer; MMP, matrix metalloprotease; TCGA, The Cancer Genome Atlas.

practice. For example, non-muscle invading BC cells often exhibit continued growth when they are suspended without anchorage within the bladder, forming a 'pedicle' which often appears similar to water grasses floating in the bladder. In contrast, muscle invasive BC often presents with an infiltrating growth with a 'moss like' appearance within the bladder. This implies the more invasive $\mathrm{BCs}$, with poor prognosis may have a higher Psoriasin expression, promoting growth and invasion, but also a more adherent 'anchored' appearing moss-like tumour. The other possibility for the difference in findings regarding cellular adhesion compared to other studies, is that the present study examined TCC, whereas other studies focused on adenocarcinomas of the bladder, within which Psoriasin may have a slightly different effect. The regulation of Psorisasin on the cellular functions of $\mathrm{BC}$ cells is yet to be fully examined although two BC cell lines were employed in the present study. In order to understand the specific adhesion mechanism occurring in these malignant lesions, further study is yet to be carried out.

It has been well established that MMPs are important within the tumour microenvironment for promoting cancer cell invasion and metastatic potential (28). In our previous study of Psoriasin in prostate cancer and pancreatic cancer, it was revealed that Psoriasin influenced cancer cell invasion via regulation of certain MMPs $(11,25)$. Similarly, upregulation of MMPs has been observed in breast cancer cells overexpressing Psoriasin (29). In the present study, BC cells with overexpression of Psoriasin were more invasive and had increased MMP9 expression, indicating the invasive effects of Psoriasin in BC could be brought about by MMPs. In the study on Psoriasin in breast cancer cells, interaction of Psoriasin with the cytoplasmic domain of the integrin $\beta 6$ subunit was implicated in the promotion of cellular invasion, however, is remains to be confirmed whether this may also be the case for BC cells, and the interaction of Psoriasin with partner proteins is worthy of further study. Future investigation using a BC patient-derived xenograft (PDX) model and organoid model will help to further validate and shed light on the therapeutic potential. Moreover, better understanding of the relevant machinery employed by Psoriasin in BC cells will help to identify the specificity, i.e. in which BC tumours Psoriasin promotes disease progression. More specific cell line- derived models, along with PDX and organoid models can then be employed.

In conclusion, increased expression of Psoriasin in BC was associated with cellular invasion, and poor survival of patients with BC. Psoriasin promoted in vitro cell growth, adhesion, and invasion of BC cell lines. MMP9 may be a key player in the Psoriasin-promoted invasiveness of BC cells. The prognostic and therapeutic potential of Psoriasin demonstrated in $\mathrm{BC}$ warrants further investigation.

\section{Acknowledgements}

Dr Jia Liu is a recipient of the Chinese Medical Research Scholarship of Cardiff University. The authors would thank Dr You Zhou for his help and advices on data analysis of the gene expression array data.

\section{Funding}

No funding was received.

\section{Availability of data and materials}

The data generated and/or analysed in the current study are available from the corresponding author on reasonable request.

\section{Authors' contributions}

LY designed the study. JL and LY wrote the manuscript. JL, ZZ, ZS, CL and XC performed the experiments. JL, ZZ, WGJ and LY performed the data analyses. FR performed the IHC 
analysis. JL, CL, YY and LY performed IHC assessment. JL, ZS, FR, YY, WGJ and LY made contributions to the revision and proof reading. All authors read and approved the manuscript and agree to be accountable for all aspects of the research in ensuring that the accuracy or integrity of any part of the work are appropriately investigated and resolved.

\section{Ethics approval and consent to participates}

Not applicable.

\section{Patient consent for publication}

Not applicable.

\section{Competing interests}

The authors declare that they have no competing interests.

\section{References}

1. Ferlay J, Soerjomataram I, Dikshit R, Eser S, Mathers C, Rebelo M, Parkin DM, Forman D and Bray F: Cancer incidence and mortality worldwide: Sources, methods and major patterns in GLOBOCAN 2012. Int J Cancer 136: E359-E386, 2015.

2. Droller MJ: Bladder cancer: State-of-the-art care. CA Cancer J Clin 48: 269-284, 1998

3. Cheng L, WeaverAL,Leibovich BC, RamnaniDM,Neumann RM, Scherer BG, Nehra A, Zincke H and Bostwick DG: Predicting the survival of bladder carcinoma patients treated with radical cystectomy. Cancer 88: 2326-2332, 2000.

4. Jemal A, Siegel R, Ward E, Murray T, Xu J, Smigal C and Thun MJ: Cancer statistics, 2006. CA Cancer J Clin 56: 106-130, 2006.

5. Madsen P, Rasmussen HH, Leffers H, Honoré B, Dejgaard K, Olsen E, Kiil J, Walbum E, Andersen AH, Basse B, et al: Molecular cloning, occurrence, and expression of a novel partially secreted protein 'psoriasin' that is highly up-regulated in psoriatic skin. J Invest Dermatol 97: 701-712, 1991.

6. Algermissen B, Sitzmann J, LeMotte P and Czarnetzki B: Differential expression of CRABP II, psoriasin and cytokeratin 1 mRNA in human skin diseases. Arch Dermatol Res 288: 426-430, 1996

7. Salama I, Malone PS, Mihaimeed F and Jones JL: A review of the S100 proteins in cancer. Eur J Surg Oncol 34: 357-364, 2008.

8. Jiang WG, Watkins G, Douglas-Jones A and Mansel RE: Psoriasin is aberrantly expressed in human breast cancer and is related to clinical outcomes. Int J Oncol 25: 81-85, 2004.

9. Moubayed N, Weichenthal M, Harder J, Wandel E, Sticherling M and Glaser R: Psoriasin (S100A7) is significantly up-regulated in human epithelial skin tumours. J Cancer Res Clin Oncol 133 253-261, 2007.

10. Tripathi SC, Matta A, Kaur J, Grigull J, Chauhan SS, Thakar A, Shukla NK, Duggal R, DattaGupta S, Ralhan R and Siu KW: Nuclear S100A7 is associated with poor prognosis in head and neck cancer. PLoS One 5: e11939, 2010.

11. Ye L, Sun PH, Martin TA, Sanders AJ, Mason MD and Jiang WG: Psoriasin (S100A7) is a positive regulator of survival and invasion of prostate cancer cells. Urol Oncol 31: 1576-1583, 2013.

12. Hu M, Ye L, Ruge F, Zhi X, Zhang L and Jiang WG: The clinical significance of Psoriasin for non-small cell lung cancer patients and its biological impact on lung cancer cell functions. BMC Cancer 12: 588, 2012.

13. Emberley ED, Alowami S, Snell L, Murphy LC and Watson PH: S100A7 (psoriasin) expression is associated with aggressive features and alteration of Jab1 in ductal carcinoma in situ of the breast. Breast Cancer Res 6: R308-R315, 2004.
14. Shubbar E, Vegfors J, Carlstrom M, Petersson S and Enerback C: Psoriasin (S100A7) increases the expression of ROS and VEGF and acts through RAGE to promote endothelial cell proliferation. Breast Cancer Res Treat 134: 71-80, 2012.

15. Sneh A, Deol YS, Ganju A, Shilo K, Rosol TJ, Nasser MW and Ganju RK: Differential role of psoriasin (S100A7) in estrogen receptor $\alpha$ positive and negative breast cancer cells occur through actin remodeling. Breast Cancer Res Treat 138: 727-739, 2013.

16. Ostergaard M, Rasmussen $\mathrm{HH}$, Nielsen $\mathrm{HV}$, Vorum $\mathrm{H}$, Orntoft TF, Wolf $\mathrm{H}$ and Celis JE: Proteome profiling of bladder squamous cell carcinomas: Identification of markers that define their degree of differentiation. Cancer Res 57: 4111-4117, 1997.

17. Celis JE, Rasmussen HH, Vorum H, Madsen P, Honoré B, Wolf $\mathrm{H}$ and Orntoft TF: Bladder squamous cell carcinomas express psoriasin and externalize it to the urine. J Urol 155: 2105-2112, 1996.

18. Ostergaard M, Wolf H, Orntoft TF and Celis JE: Psoriasin (S100A7): A putative urinary marker for the follow-up of patients with bladder squamous cell carcinomas. Electrophoresis 20: 349-354, 1999.

19. Rasmussen HH, Orntoft TF, Wolf H and Celis JE: Towards a comprehensive database of proteins from the urine of patients with bladder cancer. J Urol 155: 2113-2119, 1996.

20. Dyrskjot L, Kruhoffer M, Thykjaer T, Marcussen N, Jensen JL, Møller K and Ørntoft TF: Gene expression in the urinary bladder: A common carcinoma in situ gene expression signature exists disregarding histopathological classification. Cancer Res 64: 4040-4048, 2004.

21. Lindgren D, Sjödahl G, Lauss M, Staaf J, Chebil G, Lövgren K, Gudjonsson S, Liedberg F, Patschan O, Månsson W, et al: Integrated genomic and gene expression profiling identifies two major genomic circuits in urothelial carcinoma. PLoS One 7: e38863, 2012

22. Chandrashekar DS, Bashel B, Balasubramanya SAH, Creighton CJ, Ponce-Rodriguez I, Chakravarthi BVSK and Varambally S: UALCAN: A portal for facilitating tumor subgroup gene expression and survival analyses. Neoplasia 19: 649-658, 2017

23. Oyasu R: World health organization and international society of urological pathology classification and two-number grading system of bladder tumors. Cancer 88: 1509-1512, 2000.

24. Glaser R, Harder J, Lange H, Bartels J, Christophers E and Schroder JM: Antimicrobial psoriasin (S100A7) protects human skin from Escherichia coli infection. Nat Immunol 6: 57-64, 2005.

25. Liu Y, Bunston C, Hodson N, Resaul J, Sun PH, Cai S, Chen G, $\mathrm{Gu}$ Y, Satherley LK, Bosanquet DC, et al: Psoriasin promotes invasion, aggregation and survival of pancreatic cancer cells; association with disease progression. Int J Oncol 50: 1491-1500, 2017.

26. Zhang H, Zhao Q, Chen Y, Wang Y, Gao S, Mao Y, Li M, Peng A, He D and Xiao X: Selective expression of S100A7 in lung squamous cell carcinomas and large cell carcinomas but not in adenocarcinomas and small cell carcinomas. Thorax 63 : 352-359, 2008.

27. Winston $\mathrm{J}$ and Wolf R: Psoriasin (S100A7) promotes migration of a squamous carcinoma cell line. J Dermatol Sci 67: 205-207, 2012.

28. Ellenrieder V, Alber B, Lacher U, Hendler SF, Menke A, Boeck W, Wagner M, Wilda M, Friess H, Büchler M, et al: Role of MT-MMPs and MMP-2 in pancreatic cancer progression. Int J Cancer 85: 14-20, 2000.

29. Morgan MR, Jazayeri M, Ramsay AG, Thomas GJ, Boulanger MJ, Hart IR and Marshall JF: Psoriasin (S100A7) associates with integrin $\beta 6$ subunit and is required for $\alpha \mathrm{v} \beta 6$-dependent carcinoma cell invasion. Oncogene 30: 1422-1435, 2011.

This work is licensed under a Creative Commons Attribution-NonCommercial-NoDerivatives 4.0 International (CC BY-NC-ND 4.0) License. 